\title{
Just Hearing
}

\author{
Jon Kabat-Zinn ${ }^{1}$
}

Published online: 7 April 2017

(C) Jon Kabat-Zinn 2017

As we have noted any number of times, sound and the spaces between sounds never stop arriving at our ears. As we sit or lie someplace in meditation, if we are doing it right now, purposefully giving ourselves over to hearing . . . . just hearing what is here to be heard in this moment, nothing more.

That means we have nothing to do. The sounds are already arriving. Can we hear them? Can we be with them moment by moment, sound and the spaces between sounds met with awareness, just as we have been doing with thoughts and the spaces between them, without liking or disliking, preferring or rejecting, without judging or evaluating, cataloguing or savoring? Of course, you can intentionally do this with music, which is itself a rich and wonderful practice, but the challenge here is to practice with whatever sounds are already presenting themselves, often not always so pleasant, unless you are in pristine nature. But for this practice, it doesn't matter, because we are practicing non-attachment to pleasant or unpleasant. We are practicing just hearing.

This is called being with hearing. See if you can be here in the pure awareness of hearing. Of course, in any given moment there may very well be thoughts arising about what you are hearing, and feelings that accompany the thoughts, a range of emotions with a range of strengths and positive or negative charges, depending on what the sounds evoke, perhaps memories, perhaps fantasies, perhaps nothing. In all cases, over and

Excerpted from the book Coming To Our Senses: Healing Ourselves and the World Through Mindfulness by Jon Kabat-Zinn. Copyright ( $\odot 2005$ Jon Kabat-Zinn, Ph.D. Published by Hachette Books. All Rights Reserved.

Jon Kabat-Zinn

mindfulness@umassmed.edu

1 Center for Mindfulness, University of Massachusetts Medical School, 55 Lake Avenue North, Worcester, MA 02421, USA over again, if necessary, and it will be necessary, letting whatever is not sound be in the wings, and feature pure hearing center stage in the field of awareness, until perhaps there is no longer any center, any stage, or any wings. And perhaps there is no longer any "you" who "has" to be listening, and nothing to be listened for or to. There is, instead, just hearing, before and underneath everything else, just the bare experience of hearing.

As you give yourself over to hearing in this way, resting in the bare experience moment by moment, and coming back to it over and over again when you are carried off by the activity happening offstage and you notice it. Because as soon as you are carried off, there is thinking, and then there is the need for refocusing, for a bit of scaffolding and method to reposition your attention. All of a sudden, there is a "you" again, and a stage, and, as well, the possibility to return to hearing, pure and simple. In such moments, reformulating the intention to pay attention and to sustain attention, to surrender over and over, again and again to the hearing that is always happening without your having to do anything or exert yourself at all. In fact, in such moments, you can let go of yourself completely, opening once again to sound and the spaces between sounds, and to the silence lying inside and underneath sound. Allowing sound and awareness to be co-extensive, so that every sound or silence itself is immediately met, immediately known, without thinking, for just what it is. For that is what the essence of mind, what we have been calling "original mind," does . . . it knows non-conceptually. It already knows, without thinking, before thinking.

Dwelling in hearing, becoming hearing, merging with hearing, until - and this may be only for brief moments at firstthere is no hearer and nothing being listened for or to, nothing but hearing, hearing, hearing . . . a purity of awareness without center or periphery, without subject or object, that can be visited and touched over and over, sustaining itself as your familiarity with the practice deepens. 